\title{
Analysis of Crimping Process of Turbo Actuator Based on Multi-target Orthogonal Test
}

\author{
Bincheng $\mathrm{Li}^{1, \mathrm{a}}$, Ping $\mathrm{Liu}^{1, \mathrm{~b}^{*}}$ and Tian $\mathrm{Yu}^{1, \mathrm{c}}$ \\ ${ }^{1}$ Jiangsu University of Science and Technology, Zhenjiang, Jiangsu, China \\ alibincheng2000@126.com, b260763614@qq.com, 610013170@qq.com
}

\begin{abstract}
Keywords: Turbo Actuator; Crimping; Process Parameter; Multi-target Orthogonal test Abstract. This paper mainly studies the crimping process of turbo actuator at passenger vehicle. Firstly design a series experiments with a method of orthogonal test, then study and analysis the crimping results both by single factor visual analysis and multi-factor orthogonal matrix analysis, finally it concludes the influence tend of the main three process parameters at crimping including surface bevel $\beta$ and contour radius $\mathrm{R}$ of upper die and stamping pressure $\mathrm{P}$ on the main three forming quality indicators including $\mathrm{E}, \mathrm{F}$ and thickness $\mathrm{T}$ of actuator's cross section dimension. Moreover it puts forward an optimal process parameters combination of one actuator's crimping process and verifies the conclusion by sample statistical analysis in continuous trail run production.
\end{abstract}

\section{Introduction}

Turbo actuator, as show in Fig.1, always using at an environment with high pressure and need to move frequently, and the quality of crimping process directly affect its sealing performance and service life. Therefore it's extremely important to find the reasonable process parameters to ensure the crimping quality of Actuator.
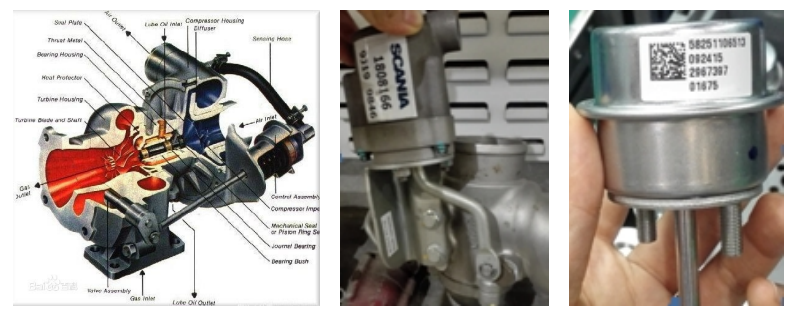

Fig.1 Turbo Actuator Models

According to the requirements of product assembly, the appearance of it need to be smooth, with no roll-in/out and warp without wrinkling and hem-out, more importantly, its dimension should absolutely meet with customer drawings. Fig. 2 is a schematic drawing of cross section key dimension requirements for a certain type of actuator from customer, the meaning of $\mathrm{E}, \mathrm{F}$, and thickness $\mathrm{T}$ as shown. Usually, customer will give minimum and maximum value for each key dimension like Emin, Emax ,Fmin, Fmax ,Tmin and Tmax, and the supplier should ensure the dimension of actuator they product be within the range of minimum and maximum value.

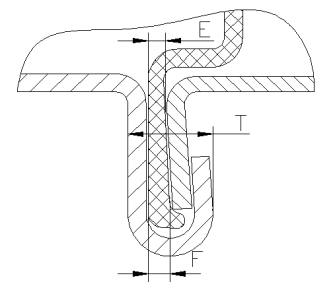

Fig.2 Key dimension of cross section

In most cases at actual production, however, it founds that key dimensions of cross section size (value of $E, F$ or $T$ ) cannot meet the requirements of the drawings at different crimping situations. Fig. 3 shows some typical cross section of unqualified products. 


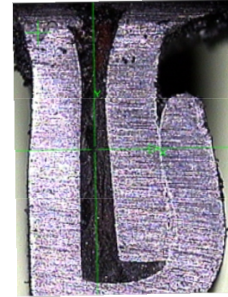

(a) $\mathrm{E}<\mathrm{E} \min$

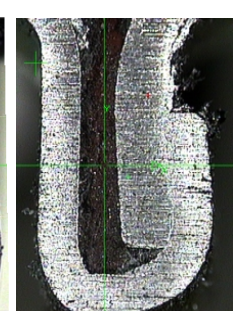

(b) $\mathrm{E}>\mathrm{E} \max (\mathrm{c}) \mathrm{F}<\mathrm{F}$ min

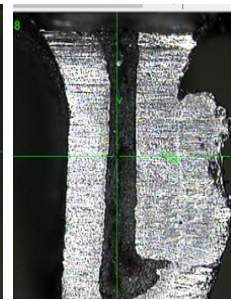

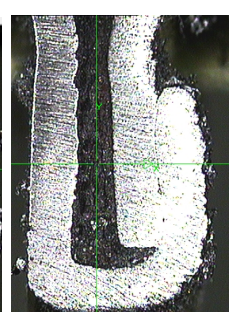

(d) $F>F$ max

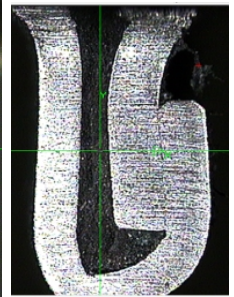

(e) $\mathrm{T}<\mathrm{T} \min$

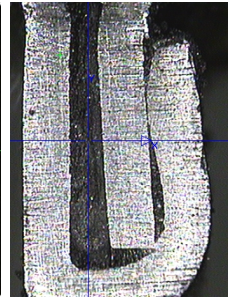

(f) $\mathrm{T}>\mathrm{T} \max$

Fig.3 Typical cross section of unqualified products

Therefore, this paper hope that by design an experiment use the method of orthogonal test and select some important process parameters which mainly effect the quality of turbo actuator after crimping, then analyzes its impact on a single forming dimension result and its cross influence on each dimension result, finally select an optimal combination of process parameters for crimping process of actuator, so as to improve the design quality of mold and reduce mold production cycle time in practical production, also to reduce scrap rate and the production cost, and hope that the conclusion get from this experiment can be verified in actual production.

\section{Organization of the Text Analysis of Crimping Process}

H.Livatyali and S.J.Larris has designed experiments to investigate the forming defects in flat surface-convex edge hemming. In the study it analysis the effects of process parameters on the final hem quality and indicate some improved process and tool design rules for flanging and hemming based on experimental finding. It concludes that the influence of the contour radius on roll was relativity stronger than the other parameters, and by increase the final hemming force can reduce roll, but further increase the force cannot ensure press the plate flatly but make some recoil. [1]

Crimping process discuss in this paper belongs to metal forming which form directly by punching, and the process can be simplified as shown in Fig.4: The two boards shown as upper die and lower die respectively, three are three components involved in this process, their name from top to bottom on the model are, in order, Cover, Body and Diaphragm. Before crimping the three components placed in the lower die according to the operation instruction, so far complete pre-assembly as shown in Fig.4 (a). After pre-assembly can start the machine, the upper die move downward under the impetus of hydraulic cylinder, then the vertical side of Body began to come into contact with cavity surface of upper die and slowly bend and get fold under the pressure, finally wrap around the Cover and Diaphragm, so far complete crimping process, as shown in Fig.4 (b).

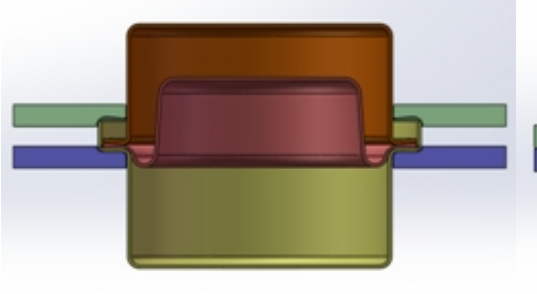

(a) Before Crimping

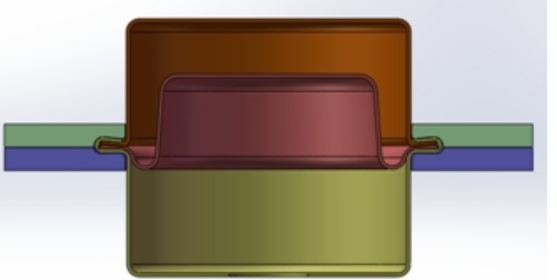

(b) After Crimping

Fig.4 Simplex Model of Crimping Process

It can be figure that in the process of crimping, the vertical side of Body has deformation mainly base on the section sharp of upper die with the contact force, and the section of upper die was shown as in Fig.5. Through reading various literature and combined with practice production experience, it indicates that the surface bevel $\beta$ and contour radius $\mathrm{R}$ of upper die and the stamping pressure $\mathrm{P}$ have greater influence on the crimping quality of actuator. [2] 


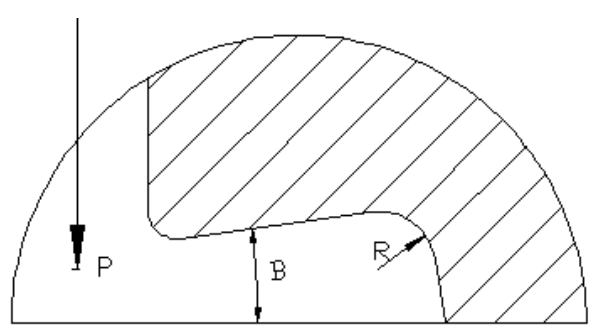

Fig.5 Section of upper die

And this article focuses on the major factors' influence may have on the actuator crimping quality under different conditions, the quality indicators are $\mathrm{E}, \mathrm{F}$ and $\mathrm{T}$ which are key cross section dimensions mentioned in previous chapter. So the experiment belongs to a cross research with multiple factors and multiple indicators. While orthogonal test design is a kind of design method to analysis multiple factors with multiple level, which makes use of the orthogonal normalized table and designed experiment scheme properly and analyzing the test results effectively. It also is an efficient, fast and economic method of experimental design which can find out the optimal formula and optimal process parameters. [3] Thus the experiment in this paper chooses the orthogonal test design method to study the crimping process of actuators. Experiment preparation list as show in Table 1.

Table 1 Experiment Preparation List

\begin{tabular}{ll}
\hline Item & Details \\
\hline Product Name & Turbo Actuator \\
Material of Body & Q/BQB402-SPCC , Y.S 175MPa,T.S 270MPa \\
Processing Equipment & Crimping Machine, Sets of mold \\
Measuring Instrument & 2D projector, Dernier caliper, Saw \\
\hline
\end{tabular}

\section{Multi-factor orthogonal experimental design}

This paper make specific research and analysis on the turbo actuator used at passenger vehicle of an industry company. According to product drawings, the value of three key dimension $\mathrm{E}, \mathrm{F}$ and $\mathrm{T}$ were required in the range as shown in Table 2, the mid-value of each range were list at below row which will be used in later.

Table 2 Key Dimension

\begin{tabular}{llll}
\hline Item & $\mathrm{E}(\mathrm{mm})$ & $\mathrm{F}(\mathrm{mm})$ & $\mathrm{T}(\mathrm{mm})$ \\
\hline Range & $0.43-0.64$ & $0.58-0.78$ & $2.84-3.10$ \\
Mid-value & 0.53 & 0.68 & 2.97 \\
\hline
\end{tabular}

In previous section of this paper has put forward three major factors that need analysis concretely. According to the scope of the equipment and practical experience chose three levels for three major factors, so the factors surface bevel $\beta$ and contour radius $\mathrm{R}$ of upper die and the stamping pressure $\mathrm{P}$ were set as shown in Table 3.

Table 3 Factors and Levels

\begin{tabular}{llll}
\hline LevellFactor & $\mathrm{B}\left({ }^{\circ}\right)$ & $\mathrm{R}\left({ }^{\circ}\right)$ & $\mathrm{P}(\mathrm{KN})$ \\
\hline 1 & 6 & 6 & 60 \\
2 & 8 & 8 & 80 \\
3 & 10 & 10 & 100 \\
\hline
\end{tabular}

The experiment becomes to be a 3 factors test with 3 levels, so select L9 $\left(3^{3}\right)$ orthogonal table for this experiment. The header design and experiment result was filed in Table 4. 
Table 4 Result of Experiment

\begin{tabular}{ccccccc}
\hline \multirow{2}{*}{ No. } & \multicolumn{3}{c}{ Factors } & \multicolumn{3}{c}{ Indicators } \\
\cline { 2 - 7 } & $\mathrm{A}: \beta$ & $\mathrm{B}: \mathrm{R}$ & $\mathrm{C}: \mathrm{P}$ & $\mathrm{E}(\mathrm{mm})$ & $\mathrm{F}(\mathrm{mm})$ & $\mathrm{T}(\mathrm{mm})$ \\
\hline 1 & 1 & 1 & 1 & 0.555 & 0.631 & 3.015 \\
2 & 1 & 2 & 2 & 0.584 & 0.611 & 3.048 \\
3 & 1 & 3 & 3 & 0.591 & 0.655 & 3.121 \\
4 & 2 & 1 & 2 & 0.521 & 0.693 & 2.925 \\
5 & 2 & 2 & 3 & 0.543 & 0.707 & 3.013 \\
6 & 2 & 3 & 1 & 0.549 & 0.683 & 2.943 \\
7 & 3 & 1 & 3 & 0.505 & 0.673 & 2.972 \\
8 & 3 & 2 & 1 & 0.521 & 0.711 & 2.891 \\
9 & 3 & 3 & 2 & 0.531 & 0.753 & 2.985 \\
\hline
\end{tabular}

In order to find the relationship between factors and indicators and find out the rule and tendency of indicators change with the change of each factor, this paper using visual analysis method which calculated average value $\mathrm{Ki}$ and range $\mathrm{Si}$ for each factor at each level. The greater Ki means the greater influence that factor has on this indicator, and the more important the factor is. [4]

According to the test result from Table 4 can calculate Ki and Si of E, F and T, as shown in Table 5. For a straightforward studying of the data, the influence tendency of each factor has already drawn in chart see in Table 5.

Table 5 Range Analysis

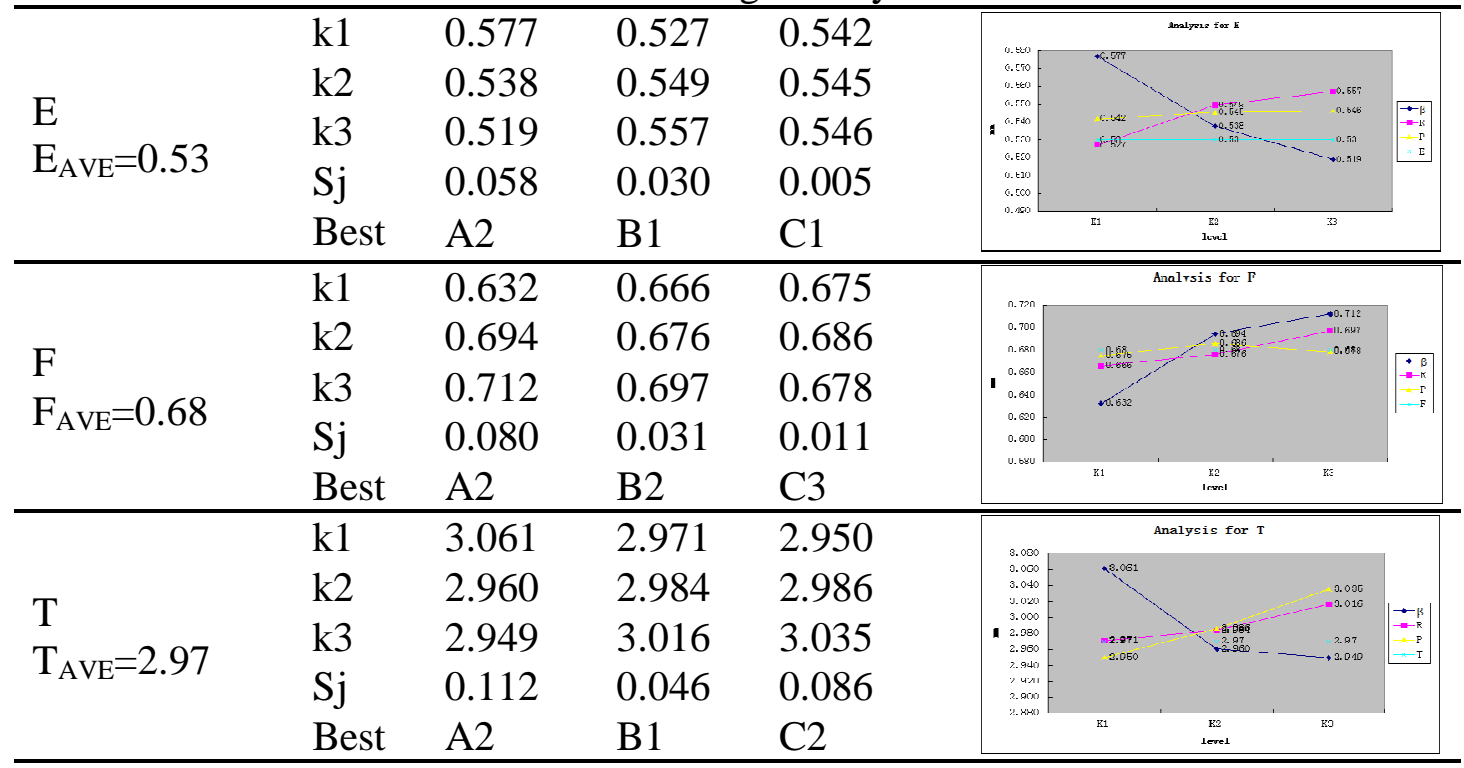

Base on the range results and analysis from Table 5, it can be seen the range of surface bevel $\beta$ has the biggest value among three factors at all indicators, which means this factor has the greatest influence on the three indicators. By finding points of three factors' Ki which is the most close to the median point among three levels comes out the optimal processing combination parameters for each indicator. As for indicator $\mathrm{E}$, the optimal solution is $\mathrm{A} 2 \mathrm{~B} 1 \mathrm{C} 1$; similarly for indicator $\mathrm{F}$, the optimal solution is A2B2C3; and indicator for T, the optimal solution is A2B1C2.

Above discussed the three factors' influence on each indicator respectively, while in practice, the three indicators are crossing influenced by each factors. Therefore, in order to overall study multiple factors' influence on multiple indicators, it needed to use matrix analysis method to do further comprehensive analysis for the optimal solution of each indicator according to the importance of the factors ,so as to chose the best process parameters combination for crimping. Key matrixes are defined as follow [3]:

Matrix 1: Suppose that orthogonal test has $l$ factors and each factor has $m$ levels, the average value of indicators of factors $A_{i}$ in level $j$ defined as $k_{i j}$. If a greater value is better for the indicator, then 
define $K_{i j}=k_{i j}$, else if a smaller value is better for the indicator, then define $K_{i j}=1 / k_{i j}$, so as to establish test index layer matrix $M$.

Matrix 2: Define $T_{i}=1 / \sum_{j=1}^{m} K_{i j}$, so as to establish factor layer matrix $T$.

The function of $K_{\mathrm{ij}} T_{i}, K_{11} T_{1}$ for example, which is equal with $K_{11} / \sum_{\mathrm{j}=1}^{m} k_{i j}$ can indicates the indicator's value percentage of factor A1 at first level among all levels. The value of $K_{11} T_{1}$ can not only reflects the degree of factor A1 influence on indicators at first level, but also can reflect the Range size of factor A1.

Matrix 3:In the orthogonal test table, $s_{i}$ is the range value of factor Ai , define $S_{i}=s_{i} / \sum_{i=1}^{l} s_{i}$ which can indicates the indicator's range value percentage for factor $\mathrm{Ai}$ among the sum range value of all factors, so as to establish horizontal layer matrix $S$.

Matrix 4: Establish weight matrix $\omega$ which indicate the influence degree on the value of indicator as defined at Eq.1:

$\omega=M T S$

)

Through those calculations can get the weight of each factor's influence on the indicators at each level. According to the weight matrix can obtain the optimal combination and find the order of all factors' influence on the indicators.

Put the result values of the three indicators get from experiments (refer to Table 4) into Eq.1 can come out the results as bellow:

$$
\begin{aligned}
& \omega_{E}=\left[\begin{array}{lllllllll}
0.0111 & 0.4129 & 0.2006 & 0.3135 & 0.0075 & 0.0039 & 0.0242 & 0.0140 & 0.0123
\end{array}\right]^{T} \\
& \omega_{F}=\left[\begin{array}{llllllllll}
0.0461 & 0.5095 & 0.1001 & 0.0515 & 0.2310 & 0.0107 & 0.0081 & 0.0063 & 0.0730
\end{array}\right]^{T} \\
& \omega_{T}=\left[\begin{array}{llllllllll}
0.0042 & 0.3742 & 0.0819 & 0.1872 & 0.0004 & 0.0001 & 0.1298 & 0.2097 & 0.0126
\end{array}\right]^{T}
\end{aligned}
$$

The average value of weight for three indicators refers as Eq.2:

$$
\begin{aligned}
\bar{\omega} & =\frac{\omega_{E}+\omega_{F}+\omega_{T}}{3} \\
\bar{\omega} & =\left[\begin{array}{llllllllll}
0.0205 & 0.4322 & 0.1275 & 0.1719 & 0.0796 & 0.0049 & 0.0540 & 0.0767 & 0.0326
\end{array}\right]^{T}
\end{aligned}
$$

From the calculation above can find the order of all factors' influence on the indicators analyses in this orthogonal experiment: The effect of factor A on this test is the most important, and then is the effect of factor $\mathrm{B}$, and the effect of factor $\mathrm{C}$ on this test is the least important. The largest weights of each factor are A2, B1 and C2, so the optimal combination for this orthogonal experiment is A2B1C2, which means that in the situation when surface bevel $\beta$ of upper die is $8^{\circ}$, contour radius $\mathrm{R}$ of upper die is $6^{\circ}$ and the stamping pressure $\mathrm{P}$ is $80 \mathrm{KN}$ can get the best crimping forming quality.

\section{Product validation}

According to the conclusion above, select 3 group of crimping parameters combination which is same as used in No.1, No.4 (who has the optimal combination parameters) and No.9 at orthogonal experiment table for continuous trail run production. Specific steps are as follows: first adjust the parameter of crimping machine of factors and levels refer to Table 3 and Table 4; then run each 
working condition for a work day ( 8 hours) and extract 32 PCS test samples at a frequency of 4 PCS/h; carefully cut the cross session of all samples with saw; finally measure the key cross section dimension of sample actuators under 2D projector. Fig. 6 shows validation results of indicator E.

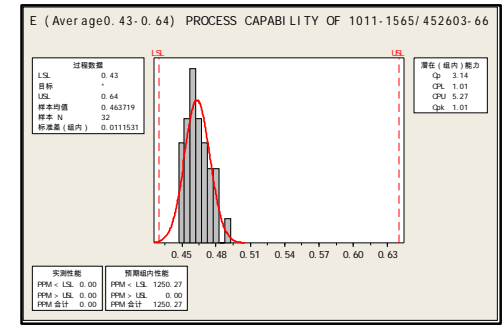

(a) $\beta=6^{\circ}, \mathrm{R}=6^{\circ}, \mathrm{P}=60 \mathrm{KN}$

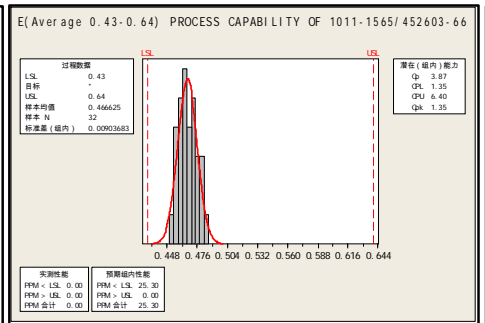

(b) $\beta=8^{\circ}, \mathrm{R}=6^{\circ}, \mathrm{P}=80 \mathrm{KN}$

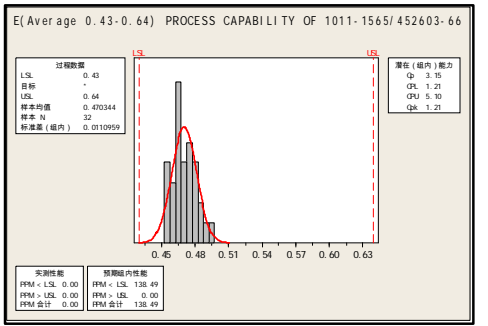

(c) $\beta=10^{\circ}, \mathrm{R}=10^{\circ}, \mathrm{P}=80 \mathrm{KN}$

Fig. 6 Validation Results

Compare the results can figure that: Samples' average value of E at No.4 is more closer to mid-value than that at No.1.Also by comparing the Cpk of three experiments, No.4 has the maximum Cpk of 1.35 among three experiments which meet the requirement of stability, and the Cpk is of No.4 is 0.34 higher than that of No.1 and 0.14 higher than No.9. This experiment verifies the practicability of the orthogonal experiment method in practice production. It means that by using the orthogonal experiment method can provide a reference for actual mold design and find an optimal crimping parameters combination.

\section{Summary}

This paper studies the crimping process of turbo actuator using the orthogonal experiment method with multi-index and multi-factor, and analyses the mainly three factors' influence on the three indicators of the crimping quality, finds that surface bevel of upper die $\beta$ has the greatest influence on the three indicators. And it puts forward an optimal process parameters combination among tested situations for the crimping process of actuator that in the situation when surface bevel $\beta$ of upper die is $8^{\circ}$, contour radius $\mathrm{R}$ of upper die is $6^{\circ}$ and the stamping pressure $\mathrm{P}$ is $80 \mathrm{KN}$ can get the best crimping forming quality. It also selected 3 group of crimping parameters combination for actual continuous trial run production for one work day, by sampling inspection and measurement analysis, verified the feasibility of the conclusion from orthogonal experiment, which means that those experiments can provide a reference for actual mold design and provide guidance an optimal crimping parameters combination selection.

\section{References}

[1] H.L ivatyali and S.J.L arris: submitted to Journal of Materials Processing Tech.(2004).

[2] C.Y.Peng, "The study of Auto-body Panel Hemming Process", M.S. thesis, Xihua University, Chengdu, Sichuan, China, 2010.

[3] X.L.Wei, B.J.Xue and Q.Zhao: submitted to Journal of Hebei University of Engineering (Natural Science Edition) (2010).

[4] J.L.Zeng, Optimization of Injection Molding Process Parameters based on CAE Technology, Ph.D. thesis, Central South University of Forestry and Technology, Hunan,Changsha,2013.

[5] Y.Z.Zhou: submitted to Journal of Mathematics in Practice and Theory (2009).

[6] Y.F.Yuan: submitted to Journal of Heibei Automotive Industry Institute (2005).

[7] Y.S.Zhang, Data analysis and Constructions of Orthogonal Arrays, M.S. thesis, East China Normal University, Shanghai, China, 2006. 
[8] Livatyali,A.Müderrisoğlu,M.A.Ahmetoğlu,N.Akgerman,G.L.Kinzel and T.Altan:submitted to Journal of Materials Processing Tech.(2000). 